\title{
Associations of Sleep Duration and Screen Time with Incidence of Overweight in European Children: The IDEFICS/I.Family Cohort
}

\author{
Viveka Guzmán $^{a} \quad$ Lauren Lissner $^{b}$ Louise Arvidsson ${ }^{c}$ Antje Hebestreit ${ }^{d}$ \\ Antonia Solea ${ }^{\mathrm{e}}$ Fabio Lauria $^{\mathrm{f}}$ Jaakko Kapriog ${ }^{g}$ Lucia A. Reisch $^{\mathrm{h}}$ Luis Moreno ${ }^{\mathrm{i}}$ \\ Regina Felsőj Stefaan de Henauw ${ }^{k}$ Tomas Veidebaum ' Wolfgang Ahrens ${ }^{d}$ \\ Monica Hunsberger ${ }^{b}$ on behalf of the IDEFICS and I.Family consortium \\ ${ }^{a}$ Division of Population Health, Royal College of Surgeons in Ireland, Dublin, Ireland; ' \\ of Public Health and Community Medicine, University of Gothenburg, Gothenburg, Sweden; 'School of Health \\ Sciences University of Skövde, Skövde, Sweden; 'Leibniz Institute for Prevention Research and Epidemiology BIPS,

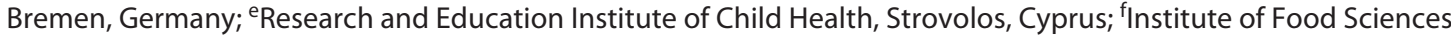 \\ National Research Council, Avellino, Italy; ${ }^{9}$ Department of Public Health University of Helsinki, Helsinki, Finland; \\ hDepartment of Management, Society and Communication Copenhagen Business School, Copenhagen, Denmark; \\ iUniversidad de Zaragoza E.U. Ciencias de la Salud, Zaragoza, Spain; 'Department of Paediatrics, Clinical Centre \\ University of Pécs, Pécs, Hungary; kDepartment of Public Health and Primary Care, Faculty of Medicine and Health \\ Sciences Ghent University, Ghent, Belgium; 'National Institute for Health Development Tallinn, Tallinn, Estonia
}

\section{Keywords}

Sleep time · Screen duration · Overweight · Obesity ·

Children

\begin{abstract}
Introduction: Over the past decades, children have been increasingly using screen devices, while at the same time their sleep duration has decreased. Both behaviors have been associated with excess weight, and it is possible they act as mutually reinforcing behaviors for weight gain. The aim of the study was to explore independent, prospective associations of screen time and sleep duration with incident overweight in a sample of European children. Methods: Data from 4,285 children of the IDEFICS/I.Family cohort who were followed up from 2009/2010 to 2013/2014 were analyzed. Hours per day of screen time and of sleep duration were reported by parents at baseline. Logistic regression analyses were carried out in separate and mutually adjusted models
\end{abstract}

controlled for sex, age, European country region, parental level of education, and baseline BMI z-scores. Results: Among normal weight children at baseline $(N=3,734)$, separate models suggest that every hour increase in screen time and every hour decrease in sleep duration were associated with higher odds of the child becoming overweight or obese at follow-up $(\mathrm{OR}=1.16,95 \% \mathrm{Cl}: 1.02-1.32$ and $\mathrm{OR}=1.23,95 \%$ Cl: 1.05-1.43, respectively). In the mutually adjusted model, both associations were attenuated slightly ( screen time $\mathrm{OR}=1.13,95 \% \mathrm{Cl}$ : 0.99-1.28; sleep duration $\mathrm{OR}=1.20,95 \%$ $\mathrm{Cl}$ : 1.03-1.40), being consistently somewhat stronger for sleep duration. Discussion/Conclusion: Both screen time and sleep duration increased the incidence of overweight or obesity by $13-20 \%$. Interventions that include an emphasis on adequate sleep and minimal screen time are needed to establish their causal role in the prevention of overweight and obesity among European children.

(c) 2021 The Author(s)

Published by S. Karger AG, Basel
C 2021 The Author(s).

Published by S. Karger AG, Basel

This is an Open Access article licensed under the Creative Commons Attribution-NonCommercial-4.0 International License (CC BY-NC) (http://www.karger.com/Services/OpenAccessLicense), applicable to the online version of the article only. Usage and distribution for commercial purposes requires written permission.
Correspondence to:

Monica Hunsberger, monica.hunsberger@gu.se 


\section{Introduction}

Although there is some evidence that children overweight prevalence has stabilized in certain countries such as the USA, Australia, and Sweden, it has done so at high levels ranging from 19 to $33 \%[1,2]$. Trends indicate that a high proportion of children who are overweight or obese maintain the excess weight into adolescence and adulthood [3, 4], which is accompanied by an increased risk of noncommunicable diseases, such as type 2 diabetes, hypertension, stroke, and certain types of cancer, such as endometrial, liver, and gastric cancer [5-7]. Moreover, consequences of overweight and obesity that were thought to be applicable only to adults are more frequently being found in children [8-11].

The mechanisms underlying the development of overweight and obesity in children are complex $[12,13]$. While some factors related to excess weight in the young population are derived from the individual's biology such as genetic factors, other predictors can be traced back to an obesogenic environment and its influence on lifestyle determinants such as diet and physical activity $[12,14]$. Thus, excess weight can be considered as a result from interactions between nonmodifiable and modifiable risk factors [15-17]. Gaining a deeper understanding of the modifiable risk factors associated with excess weight in children is of great importance to identify opportunities for prevention and public health interventions [18].

Previous studies have indicated that excessive screen time and short sleep duration might lead to overweight through several mechanisms [19-22]. For instance, by reducing opportunities for physical activity and increasing opportunities for food consumption [20, 23]. However, despite public health recommendations, children and adolescents are increasingly using screen devices, and their sleep duration has been steadily decreasing [24-28]. Furthermore, it has been previously suggested that prolonged screen time and short sleep duration may be mutually reinforcing behaviors that result in weight gain $[21,22$, 29]. Our study aims to add evidence of the relationship between the time spent using screens and sleeping, and how these habits may interact to influence changes in weight status among European children.

\section{Methods}

The data used in this study are part of the IDEFICS cohort data collected in 2009/2010 and its extension, the I.Family data collected in 2013/2014. Comprehensive information about the cohort design has been published elsewhere [30, 31].
Screen time and sleep duration calculations were derived from parental reports of their children's time spent watching TV/video/ $\mathrm{DVD} / \mathrm{PC} /$ game consoles (answer options from 0 to $>3 \mathrm{~h}$ per day) and time spent sleeping over $24 \mathrm{~h}$, on both weekdays and weekends (open-ended answer). Additional categorical variables identified compliance with the screen time recommendations of $\leq 2 \mathrm{~h}$ per day as suggested by the American Academy of Pediatrics [25] and those for adequate sleep duration suggested by the National Sleep Foundation [24]. Ten hours of sleep per day was considered as the cutpoint according to the average sleep duration recommended for the age groups represented in our sample.

Weight was measured to the nearest $0.1 \mathrm{~kg}$ with a Tanita $\mathrm{BC}$ 420 SMA scale, and height was measured to the nearest $0.1 \mathrm{~cm}$ by using a SECA 225 Stadiometer [30]. Age-specific and sex-specific BMI and BMI $z$-scores were calculated. The latest was used for model adjustment, while a binary variable was created to categorize children as normal weight (including thin) or overweight (including obese) utilizing the cutpoints for children and adolescents developed by the International Obesity Task Force (IOTF) [32].

Data on covariates were obtained through the parental questionnaire. Since previous studies have demonstrated sleep duration, screen time, and overweight differ between European regions [33-35], we grouped participants according to their country location in South-Central Europe (Cyprus, Hungary, Italy, and Spain) and North-Western Europe (Belgium, Estonia, Germany, and Sweden).

\section{Statistical Analysis}

Figure 1 shows a flowchart of the population sample included in this study. Participants with missing data on variables of interest were excluded from analysis. The study population comprised 4,825 individuals aged between 2 and 11 years old in 2009/2010. $\chi^{2}$ tests were carried out to determine differences in the participant's characteristics with respect to compliance with recommendations for screen time and sleep duration. Logistic regression was used to estimate the odds ratio (OR) corresponding to the risk of incident overweight associated with 1-h less sleep and 1 additional hour watching screens. Furthermore, categorical screen time and sleep duration variables defined by compliance with recommendations were analyzed. To determine the effect estimate change due to mutual adjustment, we calculated the difference within the resulting OR for screen and sleep variables in separate and mutually adjusted models. All models were controlled for categorical country region, sex, and parental level of education and continuous age and baseline BMI $z$-scores. Moderation was tested in the mutually adjusted model by adding an interaction term of sleep and screen times. Data analyses were performed using SPSS 24.0 (2016).

\section{Results}

A negative correlation was observed between screen and sleep times (Spearman's rho $=-0.226, p<0.001$ ). In the overall sample, baseline BMI $z$-score was the most significant predictor for becoming overweight or obese at follow-up (OR $=12.1$ per SD of BMI $z$-score, 95\% CI: 10.3-14.1). Therefore, further analysis was performed on 
Fig. 1. Flowchart of study participants.

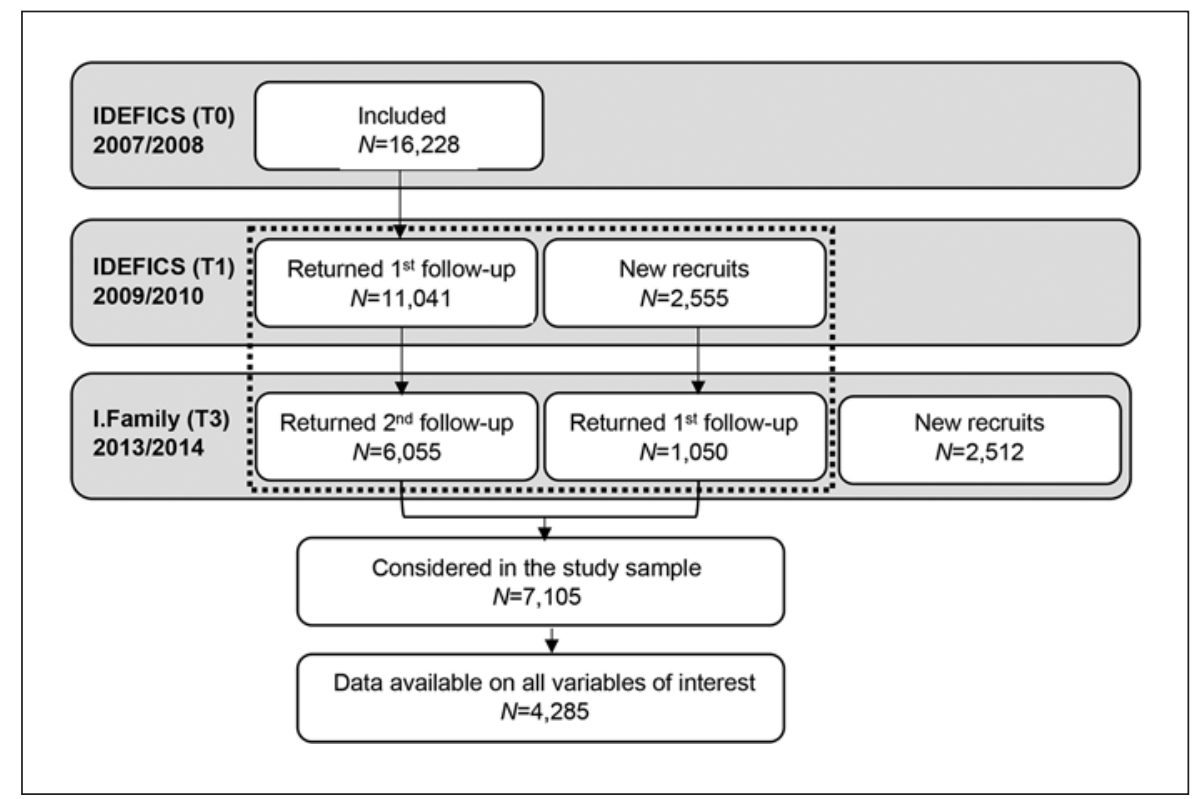

Table 1. Sociodemographic characteristics and compliance with screen time and sleep duration recommendations in the nonoverweight population at baseline $(N=3,734)$

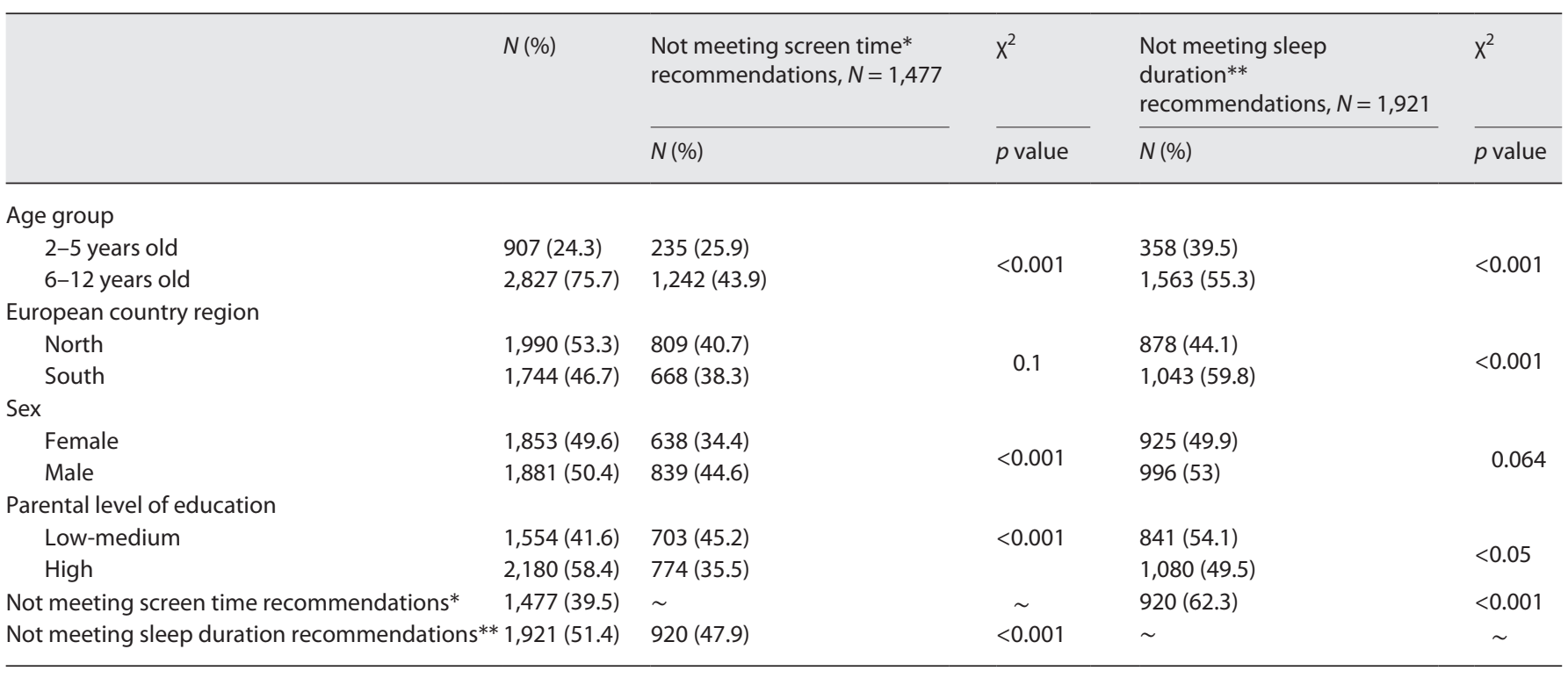

North countries: Sweden, Belgium, Estonia, and Germany; south countries: Italy, Spain, Hungary, and Cyprus. * Not meeting recommendations was considered as screen time $>2 \mathrm{~h}$ per day. ${ }^{* *}$ Not meeting recommendations was considered as sleep duration $<10 \mathrm{~h}$ per day.

samples stratified by weight status at baseline. Among those overweight or obese at baseline $(N=1,091), 228$ participants $(21 \%)$ became normal or underweight. Of those normal or underweight at baseline $(N=3,734), 387$ participants (8\%) gained weight and became overweight or obese. Analysis of the overweight and obese partici-

Sleep/Screen Time Association with Incident Overweight in European Children pants at baseline showed no significant associations of screen time and sleep duration with the odds of remaining overweight or obese in either the separate or mutually adjusted models (results not shown). Subsequent analysis focuses on the group that was not overweight or obese at baseline. 
Table 2. Non-OWOB participant prospective associations of screen time and sleep duration with the odds of becoming OWOB at follow-up $(N=3,734)$

\begin{tabular}{llll}
\hline Model & Variable & Units or categories & $\begin{array}{l}\text { Overweight } \\
\text { OR }(95 \% \mathrm{Cl})\end{array}$ \\
\hline $1 . \mathrm{a}$ & Total screen time & $(+1 \mathrm{~h})$ & $1.156^{* *}(1.015-1.316)$ \\
$1 . \mathrm{b}$ & Total sleep duration & $(-1 \mathrm{~h})$ & $1.226^{*}(1.053-1.428)$ \\
2 & Total screen time & $(+1 \mathrm{~h})$ & $1.125(0.986-1.284)$ \\
& Total sleep duration & $(-1 \mathrm{~h})$ & $1.198^{* *}(1.026-1.398)$ \\
$3 . \mathrm{a}$ & Total screen time & Meeting recommendations (reference)/not & $1.245(0.970-1.598)$ \\
$3 . b$ & Total sleep duration & meeting recommendations & \\
4 & Total screen time & & $1.286^{*}(1.006-1.645)$ \\
& Total sleep duration & & $1.216(0.946-1.564)$ \\
& & & $1.262(0.986-1.617)$ \\
\hline
\end{tabular}

Test of interaction between screen and sleep time was nonsignificant. Models 1 and 3: separate; models 2 and 4: mutually adjusted. All models controlled for country region, sex, parental level of education, BMI $z$-scores, and age. OWOB, overweight/obese; OR, odds ratio; $\mathrm{Cl}$, confidence intervals. ${ }^{*} p<0.01 .{ }^{* *} p<0.05$. $^{\wedge}$ Not meeting screen time recommendations: $>2 \mathrm{~h}$ per day; not meeting sleep duration recommendations $<10 \mathrm{~h}$ per day.

The distribution of normal and underweight participants according to their baseline characteristics and compliance with screen and sleep time recommendations is summarized in Table 1. The percentage of children not meeting either of the recommendations was $24.6 \%$. Screen time recommendations were not met by $39.5 \%$ of this sample, with significantly higher noncompliance among children in the older age group, boys, and lowmedium parental education group. Around half of the participants did not meet sleep duration recommendations, with a mean sleeping time of $9.88 \mathrm{~h}$. The proportion of noncompliance with sleep duration recommendations was significantly higher among older children, those living in Southern-Central European countries, and children from parents with low-medium level of education.

Results from the analysis of associations between screen time and sleep duration with incidence of overweight and obesity are shown in Table 2 . The separate models utilizing continuous predictor variables indicate that a $1-h$ increase of screen time and a $1-h$ decrease of sleep duration were associated with higher odds of the child becoming overweight or obese at follow-up $(\mathrm{OR}=$ 1.156, 95\% CI: $1.015-1.316$ and OR $=1.226,95 \%$ CI: $1.053-1.428$, respectively). In the mutually adjusted model, both the screen time and the sleep duration association were attenuated. The degrees of attenuation were similar in magnitude (effect estimate change $=0.031$ for sleep duration and 0.028 for screen time), although only sleep duration remained statistically significant after adjustment.
The analysis of the association between incident overweight and compliance with recommendations was only significant for those not meeting sleep recommendations in the separate model. However, we observed the same directions of association as with the continuous variables.

We carried out 2 sensitivity analyses using alternative variables: continuous BMI $z$-score instead of incident overweight or obese and the number of screen devices in the bedroom instead of hours/day of screen time. Models were adjusted for the same confounders described previously. Setting BMI $z$-scores as the outcome, the separate model indicated 1-h increase in screen time was related to relative adiposity gain ( $b=0.019,95 \%$ CI: $0.001-0.036)$, while 1 - $\mathrm{h}$ increase in sleep duration was related to relative adiposity loss ( $b=-0.037,95 \% \mathrm{CI}:-0.062$ to -0.012$)$. In the mutually adjusted models, screen time became nonsignificant, but sleep duration remained statistically significant (results not shown). Meanwhile, the sum of screen devices in the bedroom was only significant in unadjusted models, and sleep duration was slightly attenuated through mutual adjustment, but remained statistically significant (results not shown).

\section{Discussion}

We observed a high prevalence of noncompliance with screen time and sleep duration recommendations in European children, together with statistically significant prediction of incident overweight by the amount of screen 
time and sleep duration at baseline. The results also confirm that the strongest predictor of weight status in children is previous BMI $z$-scores, indicating a persistence of the condition and suggesting that efforts should focus on the earliest possible prevention of overweight. However, these efforts should be reinforced with interventions that focus on contributing factors to overweight incidence [18].

Our findings were consistent with those of previous research that suggests there is an association between shorter sleep duration and overweight [36] and longer screen time and overweight [19]. The association with screen time became nonsignificant when including sleep duration in the analysis, which may imply some residual confounding as screen time and sleep duration are correlated or a mediation effect of sleep duration in the associations between screen time and overweight. Further mediation analyses with longer observed exposure times are suggested to better understand this dynamic association.

A particular strength of our longitudinal design is that it allows for establishment of temporality in the observed associations. However, since the population included in the IDEFICS/I.Family studies is not nationally representative, generalization of the reported prevalence values requires some caution, particularly since previous evidence from the IDEFICS Swedish sample found underrepresentation of families with low education, low socioeconomic income, and foreign backgrounds [37]. Thus, the associations found in this study could particularly differ in participants with less advantageous socioeconomic status or from diverse ethnic backgrounds.

We acknowledge as a limitation that sleep duration and screen time were obtained by parental report, which could have led to nondifferential misclassification [38, 39]. However, although parental observations can vary according to the punctuality of parents and the lifestyle of the family, they are considered as a suitable method for screening large populations [40, 41].

Other dimensions of sleep quality and screen use other than duration and time of exposure may have a significant role on incident overweight and obesity and are not been considered in the present study. Objective tools for sleep assessment, such as actigraphy, could provide nuanced and complementary descriptions of sleep patterns that may influence weight trajectories and should be considered in future studies. Moreover, we recommend further studies to include information on additional screen devices that are currently widely used by children, such as tablets and smartphones. Evidence suggests that children may interact with some of these devices in different ways from traditional screen technology such as $\mathrm{TV}, \mathrm{PC}$, and videogames, due, for instance, to combinations of multiple new functionalities, as well as an increased freedom to choose the content they want to watch or who to interact with $[28,42]$. Moreover, it would also be necessary to explore if the simultaneous use of multiple screen devices may lead to unique weight outcomes.

\section{Conclusion}

Our study adds to the evidence calling for a holistic and integrated approach to prevent overweight from early age and with a life course perspective. According to our findings, strategies for overweight prevention in children may benefit from interventions that include emphasizing adequate screen time and sleep duration.

\section{Acknowledgments}

We warmly thank the parents and children who participated in the IDEFICS and I.Family studies.

\section{Statement of Ethics}

The research was conducted in accordance with the World Medical Association Declaration of Helsinki. Ethical approval was obtained from the responsible committees in each of the 8 participating countries given as follows: (1) Belgium: Ethics Committee of the Gent University Hospital, 15 October 2007, Ref. No. EC UZG 2007/243 and 19 February 2013, No. B670201316342; (2) Cyprus: Cyprus National Bioethics Committee, 12 July 2007, Ref. No. EEBK/EM/2007/16 and 21 February 2013, No.EEBK/ETI/2012/33; (3) Estonia: Tallinn Medical Research Ethics Committee (TMREC), 14 June 2007, Ref. No. 1093 and 17 January 2013, No. 128; (4) Germany: Ethics Commission of the University of Bremen, 16 January 2007 and 11 December 2012; (5) Hungary: Medical Research Council, 21 June 2007, Ref. 22-156/2007-1018EKU and 18 December 2012, 4536/2013/EKU; (6) Italy: Ethics Committee of the Local Health Authority (ASL) in Avellino, 19 June 2007, Ref. No. 2/CE and 18 September 2012, No. 12/12; (7) Spain: Ethics Committee for Clinical Research of Aragon (CEICA), 20 June 2007, Ref. No. PI07/13 and 13 February 2013, No. PI13/0012; and (8) Sweden: Regional Ethics Research Board in Gothenburg, 30 July 2007, Ref. No. 264-07 and 10 January 2013, No. 927-12. Written informed consent to participate was obtained from children and their caregivers [31]. Children $<12$ years gave their verbal assent. All study nurses and examination staff received central or local training; all the examinations and quality control adhered to the standard operation procedures. The Pan-European IDEFICS/I. Family children cohort has been registered at the ISRCTN clinical trials registry (ISRCTN62310987). 


\section{Conflict of Interest Statement}

The authors declare no conflicts of interest.

\section{Funding Sources}

V.G.'s contribution to this study was supported by the Swedish Institute. The Swedish section of this study was co-financed by the Swedish Research Council for Environment, Agricultural Sciences, and Spatial Planning (2012-00038), the Swedish Research Council (2015-02508), the ALF-agreement for western Sweden (ALFGBG-722441), and the Swedish Research Council for Health, Working Life and Welfare (FORTE Grant 2014-01994).

\section{Author Contributions}

V.G., L.L., L.A., and M.H. contributed to conceptualization; L.L., L.A., and M.H. contributed to methodology; V.G. contributed to formal analysis; V.G. contributed to investigation; L.L.,
A.H., A.S., F.L., J.K., L.A.R., L.M., R.F., S.H., T.V., and W.A. contributed to data acquisition; V.G., L.A., and M.H. contributed to data curation; V.G. contributed to writing - original draft preparation; L.L., L.A., A.H., A.S., F.L., J.K., L.A.R., L.M., R.F., S.H., T.V., W.A., and M.H. contributed to writing - review and editing. All authors have read and agreed to the published version of the manuscript.

\section{Data Availability Statement}

The data that support the findings of this study are not publicly available because they contain information that could compromise the quality of the study, but the data sharing committee is willing to receive requests. Interested researchers can contact the IDEFICS and I.Family consortia (http://www.ideficsstudy.eu/ Idefics/andhttp://www.ifamilystudy.eu/) to discuss the possibilities for data access. Clinical Trial Registry: Pan-European IDEFICS/I.Family children cohort; ISRCTN62310987; https://doi. org/10.1186/ISRCTN62310987.

\section{References}

1 Bentham J, Di Cesare M, Bilano V, Bixby H, Zhou B, Stevens GA, et al. Worldwide trends in body-mass index, underweight, overweight, and obesity from 1975 to 2016: a pooled analysis of 2416 population-based measurement studies in 128.9 million children, adolescents, and adults. Lancet. 2017.

2 Maher C, De Wilde J, Ells L, Hohepa M, Lissner L, Ogden C, et al. The plateauing prevalence of childhood obesity and overweightEvidence from nine countries. J Sci Med Sport. 2010;13:e13. Available from: http:// ovidsp.ovid.com/ovidweb.cgi? $\mathrm{T}=\mathrm{JS} \& \mathrm{PAGE}=$ reference \& $D=$ em ed $9 \& N E W S=N \&$ $\mathrm{AN}=71794370$

3 Freedman DS, Khan LK, Serdula MK, Dietz WH, Srinivasan SR, Berenson GS. The relation of childhood BMI to adult adiposity: the Bogalusa heart study. Pediatrics. 2005;115(1): 22-7.

4 Simmonds M, Llewellyn A, Owen CG, Woolacott N. Predicting adult obesity from childhood obesity: a systematic review and meta-analysis. Obes Rev. 2016;17(2):95-107.

5 Pulgaron ER, Delamater AM. Obesity and type 2 diabetes in children: epidemiology and treatment. Curr Diab Rep. 2014;14(8):508.

6 Simmonds M, Burch J, Llewellyn A, Griffiths $\mathrm{C}$, Yang $\mathrm{H}$, Owen $\mathrm{C}$, et al. The use of measures of obesity in childhood for predicting obesity and the development of obesity-related diseases in adulthood: a systematic review and meta-analysis. Health Technol Assess. 2015; 19(43):1.
7 Marie N, Flemming T, Robinson M, Thompson B, Graetz N. Global, regional, and national prevalence of overweight and obesity in children and adults during 1980-2013: a systematic analysis for the Global Burden of Disease Study 2013. Lancet. 2013;384:766-81.

8 Daniels SR. The Consequences of Childhood Overweight and Obesity. Future Child. 2006; 16(1):47-67.

9 Schipper HS, Nuboer R, Prop S, Van Den Ham HJ, De Boer FK, Kesmir C, et al. Systemic inflammation in childhood obesity: circulating inflammatory mediators and activated CD14++ monocytes. Diabetologia. 2012; 55(10):2800-10.

10 Berardis S, Sokal E. Pediatric non-alcoholic fatty liver disease: an increasing public health issue. Eur J Pediatr. 2014;173(2):131-9.

11 Lang JE, Bunnell HT, Hossain J, Wysocki T, Lima JJ, Finkel TH, et al. Being overweight or obese and the development of asthma. Pediatrics. 2018;142(6):e20182119.

12 Davison KK, Birch LL. Childhood overweight: a contextual model and recommendations for future research. Obes Rev. 2001;2(3): $159-71$.

13 Butland B, Jebb S, Kopelman P, McPherson K, Thomas S, Mardell J, et al. Foresight tackling obesities: future choices - project report. Gov Off Sci. 2007:1-161.

14 Pearson N, Biddle SJH. Sedentary behavior and dietary intake in children, adolescents, and adults: a systematic review. Am J Prev Med. 2011;41(2):178-88.

15 Sherburne Hawkins S, Law C. A review of risk factors for overweight in preschool children: a policy perspective. Int J Pediatr Obes. 2006; 1(4):195-209.
16 Weng SF, Redsell SA, Swift JA, Yang M, Glazebrook CP. Systematic review and metaanalyses of risk factors for childhood overweight identifiable during infancy. Arch Dis Child. 2012;97:1019-26.

17 Chi DL, Luu M, Chu F. A scoping review of epidemiologic risk factors for pediatric obesity: implications for future childhood obesity and dental caries prevention research. J Public Health Dent. 2017;77 Suppl 1(1):S8-31.

18 World Health Organization. Report of the comission on ending childhood obesity. World Health Organization (WHO); 2016.

19 Robinson TN, Banda JA, Hale L, Lu AS, Fleming-Milici F, Calvert SL, et al. Screen media exposure and obesity in children and adolescents. Pediatrics. 2017;140(Suppl 2):S97-101. Available from:

20 Hale L, Guan S. Screen time and sleep among school-aged children and adolescents: a systematic literature review. Sleep Med Rev. 2015;21:50-8.

21 Cain N, Gradisar M. Electronic media use and sleep in school-aged children and adolescents: a review. Sleep Med. 2010;11:735-42.

22 Lissak G. Adverse physiological and psychological effects of screen time on children and adolescents: literature review and case study. Environ Res. 2018;164:149-57.

23 Miller AL, Lumeng JC, Lebourgeois MK. Sleep patterns and obesity in childhood. Curr Opin Endocrinol Diabetes Obes. 2015;22(1): 41-7.

24 Hirshkowitz M, Whiton K, Albert SM, Alessi C, Bruni O, DonCarlos L, et al. National Sleep Foundation's updated sleep duration recommendations: final report. Sleep Heal. 2015; 1(4):233-43. 
25 American Academy of Pediatrics; Committee on Public Education. American Academy of Pediatrics: children, adolescents, and television. Pediatrics. 2001;107(2):423-6. Available from: pubmed/11158483.

26 Bucksch J, Sigmundova D, Hamrik Z, Troped PJ, Melkevik O, Ahluwalia N, et al. International trends in adolescent screen-time behaviors from 2002 to 2010. J Adolesc Health. 2016;58(4):417-25.

27 Matricciani L, Olds T, Petkov J. In search of lost sleep: secular trends in the sleep time of school-aged children and adolescents. Sleep Med Rev. 2012;16(3):203-11.

28 Roberts DF, Foehr UG. Trends in media use. Future Child. 2008;18(1):11-37.

29 Börnhorst $C$, Wijnhoven TM, Kunešová $M$, Yngve A, Rito AI, Lissner L, et al. WHO European Childhood Obesity Surveillance Initiative: associations between sleep duration, screen time and food consumption frequencies. BMC Public Health. 2015;15(1):442-11.

30 Ahrens W, Bammann K, Siani A, Buchecker K, De Henauw S, Iacoviello L, et al. The IDEFICS cohort: design, characteristics and participation in the baseline survey. Int J Obes. 2011;35 Suppl 1(1):S3-15.
31 Ahrens W, Siani A, Adan R, De Henauw S, Eiben G, Gwozdz W, et al. Cohort profile: the transition from childhood to adolescence in European children-how I.Family extends the IDEFICS cohort. Int J Epidemiol. 2017;46(5): 1394-5j. Available from: https://academic. oup.com/ije/article-lookup/doi/10.1093/ije/ dyw317.

32 Cole TJ, Lobstein T. Extended international (IOTF) body mass index cut-offs for thinness, overweight and obesity. Pediatr Obes. 2012; 7(4):284-94.

33 Hense S, Pohlabeln H, De Henauw S, Eiben G, Molnar D, Moreno LA, et al. Sleep duration and overweight in European children: is the association modified by geographic region? Sleep. 2011;34(7):885-90.

34 Hense S, Barba G, Pohlabeln H, De Henauw S, Marild S, Molnar D, et al. Factors that influence weekday sleep duration in European children. Sleep. 2011;34(5):633-9.

35 Whiting S, Buoncristiano M, Gelius P, AbuOmar K, Pattison M, Hyska J, et al. Physical activity, screen time, and sleep duration of children aged 6-9 years in 25 countries: an analysis within the WHO European childhood obesity surveillance initiative (COSI) 2015-2017. Obes Facts. 2021;14(1):32-44.

36 Li L, Zhang S, Huang Y, Chen K. Sleep duration and obesity in children: a systematic review and meta-analysis of prospective cohort studies. J Paediatr Child Health. 2017;53(4): $378-85$.
37 Regber S, Novak M, Eiben G, Lissner L, Hense S, Sandström TZWA, et al. Assessment of selection bias in a health survey of children and families: the IDEFICS Sweden-study. BMC Public Health. 2013;13(1):418.

38 Wood CT, Skinner AC, Brown JD, Brown CL, Howard JB, Steiner MJ, et al. Concordance of child and parent reports of children's screen media use. Acad Pediatr. 2019;19(5):529-33.

39 Vandewater EA, Lee SJ. Measuring children's media use in the digital age: issues and challenges. Am Behav Sci. 2009;52(8):1152-76.

40 Fisher RJ, Katz JE. Social-desirability bias and the validity of self-reported values. Psychol. Mark.. 2000;17(2):105-20.

41 Iwasaki M, Iwata S, Iemura A, Yamashita N, Tomino Y, Anme T, et al. Utility of subjective sleep assessment tools for healthy preschool children: a comparative study between sleep logs, questionnaires, and actigraphy. J Epidemiol. 2010;20(2):143-9. Available from: http://joi.jlc.jst.go.jp/JST.JSTAGE/jea/ JE20090054? from $=$ CrossRef.

42 Rideout V, Foehr U, Roberts D; Henry J. Kaiser Family Foundation Study. Generation M2: media in the lives of 8-to 18-year-olds [Internet]. 2010. Available from: https://eric. ed.gov/?id=ED527859. 